\title{
Öğretmen Adaylarının Etkin Vatandaşlık Algılarının İncelenmesi
}

\author{
DOI: $10.26466 /$ opus.537074 \\ * \\ Yavuz Değirmenci ${ }^{*}$-Burak Eskici** \\ * Dr,Öğr. Üyesi Bayburt Üniversitesi, Eğitim Fakültesi, Merkez / Bayburt / Türkiye \\ E-Posta: ydegirmenci@bayburt.edu.tr \\ ORCID: 0000-0003-3417-1775 \\ ** Yüksek Lisans Öğrencisi, Bayburt Üniversitesi, Sosyal Bilimler Enstitüsü, Bayburt, Türkiye \\ E-Posta: eskiciburak 69@hotmail.com \\ ORCID: $\underline{0000-0001-7062-2858}$
}

\section{Öz}

Bu araştırmanın amacı sını öğretmeni adaylarının günümüzde popülerliği ve önemi her geçen gün artan etkin vatandaşlık kavramına ilişkin algılarını incelemektir. Araştırma, 2016-2017 eğitim öğretim yılının güz döneminde öğrenim gören, 82'si kız ve 56'sı erkek olmak üzere toplam 138 sinıföğretmeni adayı ile yürüttülmüştür. Çalışmada, nitel araştırma yöntemlerinden biri olan olgu bilim (fenomenoloji) deseni kullanılmıştır. Çalışma grubunun etkin vatandaşlık kavramıyla ilgili görüş ve düşünceleri tek cümleden oluşan bir görüşme formuyla toplanmıştır. Verilerin analizinde ise içerik analizi tekniği kullanılmıştır. Araştırmadan elde edilen bulgulara göre öğretmen adayları etkin vatandaşlık kavramına yönelik toplam 78 farkl ve geçerli metafor üretmişlerdir. Bu metaforlar ortak özelliklerine göre $(n=7)$ farklı kategori altında toplanmıştır. Araştırma sonucuna göre etkin vatandaşlık kavramıyla ilgili metaforların daha çok "sosyal sorumluluğu yüksek olarak etkili vatandaşlık" kategorisinde yer aldığı tespit edilmiştir. Ayrıca katılımcıların bu kavrama yönelik en çok tercih ettiği metaforlar ise sorumluluk sahibi kişi, arı, ă̆aç, su, elmas, karınca, öğretmen ve tohum metaforları olmuştur.

Anahtar Kelimeler: Etkin vatandaşlık, metafor, öğretmen adayı 


\title{
Examination of Prospective Teachers' Perceptions of Active Citizenship
}

\begin{abstract}
The purpose of this particular research is to examine prospective classroom teachers' perceptions of active citizenship, a concept which has been increasing its popularity. The population of the study consists of 138 prospective classroom teachers, 82 of whom are females and 56 males, who were being educated in the Fall semester of 2016-2017 Academic Year. Phenomenology, a qualitative research method, has been employed in the research. The views and thoughts of the target population regarding the concept of active citizenship have been collected by use of an interview form which consists of a single sentence. The data collected were analyzed by the technique of content analysis. According to the findings of the research, the prospective teachers came up with 78 different and valid metaphors about the concept of active citizenship. Those metaphors are grouped under 7 different categories according to their common characteristics $(n=7)$. The results of the research revealed that the metaphors about the concept of active citizenship are mostly in the category of "active citizenship as having high level of social responsibility." Besides, the participants' most preferred metaphors about the concept were the metaphors of responsible person, bee, tree, water, diamond, ant, teacher and seed.
\end{abstract}

Keywords Active citizenship, metaphor, teacher candidate 


\section{Giriş}

$\mathrm{Bu}$ günün karmaşık ve hızlı değişebilen dünyasında toplumların sorgulayıc1, eleştirel ve hızlı düşünebilen, keşfedici, mevcut durumda ve gelecekle ilgili bilinçli kararlar alabilen yetilere sahip bireylere ihtiyacı vardır. Bununla birlikte toplumlar, yerel ve küresel ölçekte yaşanan gelişmelere karşı ilgili, sorumluluklarının farkında, sosyal olaylara ve problemlere karşı duyarlı, yeri geldiğinde etkin rol alabilen vatandaşlara gereksinim duyarlar. Bu nedenle ihtiyaç duyulan bireylerin yetiştirilmesinde eğitime önemli sorumluluklar düşerken, burada vatandaşlık eğitimi ve vatandaşlık yaklaşımları ön plana çıkmaktadır.

Vatandaşlık eğitimi, aslında vatandaşlık kavramının gelişimiyle başlamış ve vatandaşlık anlayışında yaşanan gelişmeler doğrultusunda şekillenmiştir. Vatandaşlık anlayışındaki temel değişimlerin ise ulusların yaşadıkları sosyal, siyasal, ekonomik ve kültürel değişimler ile paralellik gösterdiği, bu nedenle de her ulusun sahip olduğu vatandaşlık anlayışının ve buna bağlı olarak uyguladığı vatandaşlık eğitiminin birbirinden farklı olduğu söylenebilir (Ersoy, 2007). Vatandaşlık kavramının anlaşılmasına yönelik sınırlar, vatandaşlık eğitiminin kapsamının ortaya konulmasında belirleyici olmaktadır. Özellikle son yıllarda literatürde sıkça yer alan aktif veya etkin vatandaşlık kavramı geniş kapsamlı evrensel bir yaklaşım olarak kabul görmekte (Hablemitoğlu ve Özmete, 2012) ve farklı şekillerde tanımlanmaktadır. Etkili vatandaşlık, demokratik toplumlarda bireylerin vatandaşlık konumlarının gerektirdiği bilgi, beceri ve değerlere sahip olma durumu (NCSS, 2002) iken, etkin vatandaş ise çevresindeki olaylara müdahale edebilen ve bundan sonuç alabilen kişi (Çevik-Kansu, 2015) olarak tanımlanabilir. Her ne kadar etkin vatandaşlı̆̆ın tam olarak ne olduğu konusunda genel kabul gören bir tanımlama bulunmasa da (Kennedy, 2007) vatandaşların katılımı vurgusu yapılan çalışmalarda ağırlıklı olarak dile getirilmektedir. Bu bağlamda etkin vatandaşlık, vatandaşların üyesi oldukları toplumlardaki problemleri tanımlamada, bu problemlerle baş etmede ve aynı zamanda yaşam kalitelerini artırmada aktif bir şekilde yer almalarını sağlayan imkânlara sahip olmaları şeklinde tanımlanabilir (Kara, Topkaya ve Şimşek, 2012). Etkin vatandaşlık yeni bir kavram olmasa da 1990'l1 yıllardan sonra Avrupa Komisyonu'nun bu konudaki çalışmaları sonrasında giderek önem kazanmaya başladı ve 
Avrupa politikalarında teşvik edilen önceliklerden biri haline geldi (Council of EU, 2009). Bununla birlikte etkin vatandaş yetiştirmeye yönelik eğitimler sadece vatandaşlık bilgisine yönelik derslerde değil, aynı zamanda eğitim müfredatında yer alan diğer disiplinlerde de verilmesi gerektiği üzerinde durulur (Akyol ve Özünal, 2015). Sosyal bilgiler ve coğrafya eğitimi etkin vatandaşlık eğitiminin verildiği disiplin alanlarından bazılarını oluşturur. Nitekim etkin vatandaşlık eğitiminde sosyal bilgiler dersi mihver bir ders olarak görülmekte (Kara, Topkaya ve Şimşek, 2012; Çermik, Çalışoğlu ve Tahiroğlu, 2016) ve bu alanda yapılan çalışmalar dikkat çekmektedir. Ancak bu konuda coğrafya eğitiminin önemi de yadsınamaz. Çünkü coğrafya inceleme alanı ve inceleme konusu itibariyle ve sahip olduğu içerikle etkin vatandaşlığın gelişimine önemli katkılar sunabilir. Nitekim coğrafya yerel ve küresel ölçekte vatandaşlıkla ilgili problemlerin çözümüne ve etkin vatandaşlı̆̆ın gelişimine katkılar sunmuştur (Bednarz, 2003). Bu konuda yenilenen coğrafya öğretim programı incelendiğinde önceki programlardan farklı olarak en dikkat çekici yenilik öğrencilere yönelik bazı yetkinlik alanlarının belirlenmesidir. Bu yetkinlik alanlarından birisi de sosyal ve vatandaşlıkla ilgili yetkinlik alanıdır. Bu yetkinlik bireylerarası ve kültürlerarası yetkinlikleri içermekte, bireylerin farklılaşan toplum ve çalışma hayatına etkili ve yapıcı biçimde katılmalarına imkân tanıyacak; gerektiğinde çatışmaları çözecek özelliklerle donatılmasını sağlayan tüm davranış biçimlerini kapsamaktadır. Vatandaşlıkla ilgili yetkinlik alanı ise bireyleri, toplumsal ve siyasal kavram ve yapılara ilişkin bilgiye, demokratik ve aktif katılım kararlılığına dayalı, medeni hayata tam olarak katılmaları için çeşitli açılardan donatmak şeklinde ifade edilmiştir (CDÖP, 2018).

Milli Eğitim Bakanlığı'nın yenilenen temel eğitim düzeyindeki sosyal bilgiler öğretim programı incelendiğinde "etkin vatandaşlık" adı altında ayrıca çeşitli kazanımlardan oluşan bir öğrenme alanına yer verilmiştir. $\mathrm{Bu}$ öğrenme alanında vatandaşlık kavramının önemi, bireyin toplum içerisindeki hak ve sorumluluklarının farkına varması, grup, kurum ve sosyal örgütlerin yapısı ve rolleri, bunlar arasındaki etkileşim, toplumsal sorunlar ve bu sorunların nasıl çözülebileceğinin bireyler tarafından fark edilmesine yönelik çeşitli açıklamalar yer almaktadır (MEB, 2018) ve önemine vurgu yapılmaktadır. Sosyal olay ve problemlerin dağ gibi 
olduğu özellikle günümüz dünyasında bireylere daha fazla sorumluluk düşmekte ve bu olaylar karşısından daha etkin rol almaları beklenmektedir. Programlarda istenen hedeflere ulaşmak için ilk önce bu sürecin yürütücüsü ve baş aktörlerinden biri olan öğretmenlerin etkin vatandaşlık kavramının ne olduğunu ve bu kavramın öneminin farkında olması gerekir. Akbaş ve Uzunöz (2011)'e göre bireyin herhangi bir alanda veya konuda bilgi sahibi olması, çeşitli fikirler geliştirmesi için öncelikle o alana ait temel kavramları doğru ve bilimsel gerçeklere uygun olarak kazanması önemlidir. Bu nedenle öğretmen adaylarının etkin vatandaşlık kavramına yükledikleri anlam veya semboller, algı ve inanışlarını ortaya koymak amacıyla metaforlardan yararlanılmıştır. Metaforlar, bir konu veya kavram hakkında bireylerin inançları, kişisel deneyim ve bilişsel yapılarını ortaya koymak için en güçlü araçların başında gelir (Mahlios ve Maxson, 1998; Kalra ve Baveja, 2012).

Metaforlar, genel olarak söylemlerimizi süsleme amacıyla kullandığımız bir söz sanatı olarak tanımlanabilir (Morgan, 1997). Çoğu zaman kavramlar algılanırken başka kavramlarla olan ortak özellikleri akla gelir veya zihinde bu kavramlarla ilgili çeşitli benzetmeler oluşturulur. Bu nedenle metaforlar, anlaşılması zor kavramların benzetmeler yapılarak bilinen kavramlarla anlatılması şeklinde formal ve informal öğrenmelerde karşımıza çıkmaktadır (Geçit ve Gencer, 2011). Seferoğlu, Korkmagil ve Özlü (2009)'ye göre ise metaforlar, dünyayı ve gerçek yaşantılarımızı nasıl algıladığımızla ilgili pencerelerdir. Dolayısıyla algılama, kişilerin sahip oldukları bilgilerin ana kaynağını oluşturur ve deneyimlerden bağımsız düşünülemez (Akturan ve Esen, 2008). Bu nedenle özellikle eğitim alanında olay, olgu, yaşantı veya kavramlarla ilgili bireylerin alg1 veya düşüncelerini ortaya koyan çalışmalarda metaforların sıklıkla kullanıldı̆̆ı görülmektedir.

İlgili literatür incelendiğinde etkin vatandaşlıkla ilgili ulusal ve uluslar arası alanda (Hoskins, 2006; Ersoy, 2007; Peterson ve Knowles, 2009; İbrahimoğlu, 2009; Phillips, 2011; Chistolini, 2013; Zepke, 2013; Şimşek ve diğ. 2017; Aydın ve Çelik, 2017; Eryılmaz, Bursa ve Ersoy, 2018) pek çok çalışmanın yer aldığı ancak etkin vatandaşlık eğitiminin küçük yaşlardan itibaren verildiği temel eğitim düzeyinde öğretmen algılarını ortaya koyan çalışmaların sınırlı olduğu görülmüştür. Her ne kadar dersler ve müfredatlar etkin vatandaşlığın gelişimine katkı sağlasalar da bu konuda 
öğretmenlerin de rolü büyüktür (Ethridge, 2006). Bu bağlamda vatandaşlık eğitimi ve vatandaşlık bilinci bireylere küçük yaşlardan itibaren planlı bir şekilde kazandırılmalıdır (Patrick, 2003; Ersoy, 2007; Çevik-Kansu, 2015; Şimşek ve diğ., 2017). Bu nedenle vatandaşlık eğitiminin temellerinin erken yaşlardan itibaren atıldığı düşünüldüğünde bu eğitimi verecek olan sınıf öğretmeni adaylarının etkin vatandaşlık kavramına yönelik algıları ve farkındalıkları önemlidir. Araştırmada ayrıca şu alt sorulara da yanitlar aranmıştır:

- Sınıf öğretmeni adaylarının "etkin vatandaşlık" kavramını betimlerken genellikle kullandıkları metaforlar nelerdir?

- Etkin vatandaşlık kavramına yönelik öğretmen adaylarının oluşturmuş oldukları metaforlar ortak özelliklerine göre hangi kategoriler altında toplanmaktadır?

\section{Yöntem}

Öğretmen adaylarının etkin vatandaşlık kavramına yönelik algılarının incelendiği bu araştırmada nitel araştırma yaklaşımlarından biri olan olgu bilim (fenomenoloji) deseni kullanılmıştır. Bu desen gerçek yaşamda farkında olduğumuz ancak derinlemesine ve ayrıntılı bir anlayışa sahip olmadığımız olgulara odaklanmak şeklinde ifade edilir. Bu olgular, yaşadığımız dünyada olaylar, deneyimler, algılar, kavramlar, yönelimler ve durumlar gibi çeşitli şekillerde karşımıza çıkar. Bu nedenle bize tam anlamıla yabancı olmayan ancak anlamını bütünüyle de kavrayamadığımız olguları araştırmak için uygun görülen bir desendir (Yıldırım ve Şimşek, 2011). Fenomenolojik çalışmalar, kişilerin bir fenomen veya kavramla ilgili yaşanmış deneyimlerinin ortak anlamını tanımlar (Creswell, 2016). Araştırmada öğretmen adaylarının etkin vatandaşlıkla ilgili deneyimleri, algıları, görüşleri ve bu kavrama yükledikleri ortak anlamları ortaya koymak amacıyla bu desenin seçimi uygun görülmüştür.

\section{Çalışma Grubu}

Araştırmanın çalışma grubunu 2016-2017 eğitim-öğretim yılının güz döneminde Bayburt Üniversitesi Eğitim Fakültesi Sınıf Öğretmenliği Bölümü'nde öğrenim gören, daha önce coğrafya ve vatandaşlık eğitimine 
yönelik dersler almış toplam 138 öğretmen adayı oluşturmaktadır. Çalışma grubuna ilişkin veriler tablo 1'de verilmiştir.

Tablo 1. Çalışma grubuna ait nitelikler

\begin{tabular}{lll}
\hline Cinsiyet & Frekans $(f)$ & Yüzde (\%) \\
\hline Kiz & 82 & 59.43 \\
Erkek & 56 & 40.57 \\
Toplam & 138 & 100 \\
\hline
\end{tabular}

Tablo 1 incelendiğinde, araştırmaya katılan sınıf öğretmeni adaylarının yarıdan fazlasını n=82 (\% 59,43) kız öğrenciler oluştururken, grupta yer alan erkek öğrenciler ise çalışma grubunun \% 35,53'ünü $\quad(n=56)$ oluşturmaktadır.

\section{Verilerin Toplanması}

Araştırmanın bu aşamasında veri toplama aracı geliştirilirken ilk olarak ilgili literatür (Shaw ve Mahlios, 2008; Saban, 2008; Seferoğlu, Korkmazgil ve Ölçü, 2009; Kalra ve Baveja, 2012; Turan, 2017; Aydın ve Çelik, 2017) incelenmiş ve daha sonra araştırmaya katılan öğretmen adaylarının etkin vatandaşlık kavramına yönelik sahip oldukları metaforları toplamak için katılımcılara ilgili çalışmalarda da kullanılan "etkin vatandaşlık.......ela benzer/gibidir....... çünkü....." şeklinde yarım bırakılmış ve katılımcılar tarafından doldurulması istenen bir yarı yapılandırılmış form verilmiştir. Öğretmen adaylarının etkin vatandaşlık kavramına ilişkin sahip oldukları metaforları "çünkü" den sonra gerekçeleriyle birlikte yazmaları istenmiştir. Bu işlem için katılımcılara yaklaşık 20 dakikalık bir süre verilmiş ve bu formlardan elde edilen veriler araştırmanın temel veri kaynağını oluşturmuştur.

\section{Verilerin Analizi}

Araştırmada katılımcılardan elde edilen verilerin çözümlenmesinde içerik analizi tekniği kullanılmıştır. İçerik analizi, elde edilen verilerin çeşitli şekillerde tasnif edildiği, sosyal bilim alanlarında sıklıkla kullanılan ve çeşitli açılardan benzerlik gösteren verileri belirli kavram ve temalar 
altında bir araya getirmek, bu verileri okuyucuların daha kolay anlayabileceği bir şekilde düzenleyerek yorumlamaktır (Bilgin, 2014; Yıldırım ve Şimşek, 2011; Büyüköztürk ve diğ., 2010). Bu süreçte öğretmen adaylarından elde edilen metaforlar, Saban (2009) tarafından kullanılan çeşitli aşamalar dikkate alınarak değerlendirilmiştir. İlk olarak adlandırma aşamasında sınıf öğretmeni adaylarının etkin vatandaşlığa yönelik geliştirmiş olduğu metaforlar alfabetik sıraya göre düzenlenmiştir. Daha sonra ikinci aşama olan tasnif etme/eleme aşamasında geliştirilen her bir metafor ayrı ayrı incelenerek metaforun konusu ve kaynağ ilişkiye bakılmış ve bu ilişkinin anlamlı olmasına dikkat edilmiştir. Bu inceleme sonucunda araştırmaya katılan tüm öğretmen adaylarının geçerli metafor üretemedikleri görülmüş. Katılımcıların, metafor kaynağ içermeyen veya metaforun gerekçesinin sunulmadığı bazı formları değerlendirilmeye tabi tutulmamıştır. Bu eleme sonrasında araştırmaya katılan 138 sınıf öğretmeni adayı etkin vatandaşlık kavramıla ilgili toplam 78 geçerli metafor üretmişlerdir. Kategori geliştirme aşamasında ise öğretmen adaylarının geliştirmiş oldukları 78 geçerli metafor ortak özelliklerine göre 7 farklı kategori altında toplanmıştır. Saban (2009)'nın belirtiği son aşamada ise çalışmanın geçerlik ve güvenirlik aşaması dikkate alınmıştır. Araştırmanın geçerliği için elde edilen verilerin raporlandırılması ve araştırmacının çalışma sonuçlarına nasıl ulaştığı araştırmanın geçerliliği adına önemlidir (Yıldırım ve Şimşek, 2011). Çalışmanın güvenirliği için ise elde edilen kavramsal kategoriler altında sunulan metaforların ilgili kategoriyi temsil edip etmediğini belirlemek amacıyla uzman görüşüne başvurulmuştur (Creswell, 2016). Oluşturulan tüm metafor $(n=78)$ ve kategoriler $(n=7)$ bir liste halinde 2 farklı alan uzmanlarına verilmiş. Daha sonra uzman görüşlerinden gelen dönütler de dikkate alınarak araştırmanın (Güvenirlik Formülü = Görüş birliği / Görüş birliği + Görüş ayrılığı) güvenirliği hesaplanmıştır (Miles ve Huberman (1994). Uzman görüşleri sonrasında bir (asker) metaforun araştırmacıdan farklı olarak farklı bir kategori ile ilişkilendirildiği görülmüş. Bu nedenle güvenirlik 78/78+1=0.98 olarak hesaplanmıştır. Bu sonuç araştırmanın güvenirliği için yeterli olduğunu gösterir. Daha sonra veriler, bilgisayar ortamına aktarılarak yüzde (\%) ve frekansları (f) hesaplanmıştır. 


\section{Bulgular}

Araştırmanın bu bölümünde sınıf öğretmeni adaylarının "etkin vatandaşlık" kavramına yönelik sahip oldukları metaforlar ve metafor kategorileri tablolar halinde sunularak yorumlanmıştır. Tablo 2'de katılımcıların "etkin vatandaşlık" kavramıyla ilgili geliştirmiş oldukları metaforlar verilmiştir.

Tablo 2. Öğretmen adaylarının etkin vatandaşlık algılarına yönelik geliştirdikleri meteforlar

\begin{tabular}{|c|c|c|c|c|c|}
\hline Oluşturulan Metaforlar & Siklık & $\%$ & Oluşturulan Metafor & Siklık & $\%$ \\
\hline 1-Sorumluluk sahibi & 13 & 9.42 & 40-Çiçek & 1 & 0.72 \\
\hline 2-Ar1 & 11 & 7.97 & 41-Devlet adamı & 1 & 0.72 \\
\hline 3-Ağaç & 6 & 4.34 & 42-Dinamo & 1 & 0.72 \\
\hline 4-Su & 5 & 3.62 & 43-Ekmek & 1 & 0.72 \\
\hline 5-Elmas & 4 & 2.89 & 44-Enzim & 1 & 0.72 \\
\hline 6-Karınca & 4 & 2.89 & $45-\mathrm{Ev}$ & 1 & 0.72 \\
\hline 7-Öğretmen & 4 & 2.89 & 46-Fabrika & 1 & 0.72 \\
\hline 8-Tohum & 4 & 2.89 & 47-Gökkuşağ1 & 1 & 0.72 \\
\hline 9-Duyarlı insan & 4 & 2.89 & 48-Hayat damarı & 1 & 0.72 \\
\hline 10-Çalışkan öğrenci & 3 & 2.17 & 49-İnsan kalbi & 1 & 0.72 \\
\hline 11-Aktif birey & 3 & 2.17 & 50-İnsan vücudu & 1 & 0.72 \\
\hline 12-Altın & 2 & 1.44 & 51-İstasyon & 1 & 0.72 \\
\hline 13-Anne & 2 & 1.44 & 52-İşlenmiş kumaş & 1 & 0.72 \\
\hline 14-Araştırmacı & 2 & 1.44 & 53-İşleyen demir & 1 & 0.72 \\
\hline 15-Bilgisayar & 2 & 1.44 & 54-Kaleci & 1 & 0.72 \\
\hline 16-Girişimci & 2 & 1.44 & 55-Lokomotif & 1 & 0.72 \\
\hline 17-Güneş & 2 & 1.44 & 56-Makine & 1 & 0.72 \\
\hline 18-İnsan & 2 & 1.44 & 57-Makinist & 1 & 0.72 \\
\hline 19-Kişilik gelişimi & 2 & 1.44 & 58-Mum & 1 & 0.72 \\
\hline 20-Örnek kişi & 2 & 1.44 & 59-Müzisyen & 1 & 0.72 \\
\hline 21-Sosyal adalet & 2 & 1.44 & $\begin{array}{l}\text { 60-Müzik } \\
\text { öğretmeni }\end{array}$ & 1 & 0.72 \\
\hline 22-Aile & 1 & 0.72 & 61-Nefes & 1 & 0.72 \\
\hline 23-Ambulans & 1 & 0.72 & 62-Okul & 1 & 0.72 \\
\hline 24-Araç motoru & 1 & 0.72 & 63-Okyanus & 1 & 0.72 \\
\hline 25-Asker & 1 & 0.72 & 64-Organ & 1 & 0.72 \\
\hline 26-Aslan & 1 & 0.72 & 65-Orkestra elemanı & 1 & 0.72 \\
\hline 27-Ata & 1 & 0.72 & 66-Politikacı & 1 & 0.72 \\
\hline 28-Aydınlık & 1 & 0.72 & 67-Saat & 1 & 0.72 \\
\hline 29-Ayna & 1 & 0.72 & 68-Sosyal katılım & 1 & 0.72 \\
\hline 30-Bankamatik & 1 & 0.72 & 69-Süper kahraman & 1 & 0.72 \\
\hline 31-Başbakan & 1 & 0.72 & 70-Şehit & 1 & 0.72 \\
\hline 32-Beyaz gömlek & 1 & 0.72 & 71-Taksi & 1 & 0.72 \\
\hline 33-Bilim & 1 & 0.72 & 72-Teknoloji & 1 & 0.72 \\
\hline
\end{tabular}




\begin{tabular}{llllll} 
34-Bilinçli birey & 1 & 0.72 & 73-Temel yapıtaşı & 1 & 0.72 \\
\hline 35-Binadaki kolon & 1 & 0.72 & 74-Toprak & 1 & 0.72 \\
\hline 36-Bir elin parmakları & 1 & 0.72 & 75-Trafik 1şı̆̆ & 1 & 0.72 \\
\hline 37-Can suyu & 1 & 0.72 & 76-Vatan toprağ & 1 & 0.72 \\
\hline 38-Çağdaş insan & 1 & 0.72 & 77-Yağmur damlası & 1 & 0.72 \\
\hline 39-Çark dişlisi & 1 & 0.72 & 78-Yıldız & 1 & 0.72 \\
\hline
\end{tabular}

Tablo 2 incelendiğinde, araştırmaya katılan öğretmen adayları tarafından etkin vatandaşlık kavramına yönelik toplam 78 farklı metafor geliştirildiğ $i$ görülmektedir. Katılımcların \% 9.42'sinin ( $\mathrm{f}=13)$ etkin vatandaşlık kavramını "sorumluluk sahibi kişi "ye benzettikleri görülmektedir. Katılımcıların \% 7.97'si ise ( $\mathrm{f}=11)$ etkin vatandaşlığı "arı" ya benzettikleri görülmektedir. Bunun dişında etkin vatandaşlık kavramının en çok benzetildiği diğer metaforlar ise sirasıyla "ağaç" \% 4.37 (f=6), "su" \% 3.62 (f=5), "elmas" \% 2.89 (f=4), "karnca" \% 2.89 (f=4), "öğretmen" \% 2.89 (f=4), "tohum" \% 2.89 (f=4), "duyarlı insan" \% $2.89(\mathrm{f}=4)$, "çalı̧̧kan öğrenci" \% $2.17(\mathrm{f}=3)$, "aktif birey" \% $2.17(\mathrm{f}=3)$, "altın" \% 1.4. ( $\mathrm{f}=2)$, "anne" \% 1.4. ( $\mathrm{f}=2)$, "araştırmact" \% 1.4. (f=2), "bilgisayar" \% 1.4. (f=2), "girişimci" \% 1.4. ( $\mathrm{f}=2)$, "güneş" \% 1.4 . $(\mathrm{f}=2)$, "insan" \% 1.4. (f=2), "kişilik gelişimi" \% 1.4. ( $\mathrm{f}=2)$, "örnek kişi" \% 1.4. $(\mathrm{f}=2)$ ve "sosyal adalet" \% 1.4. ( $\mathrm{f}=2)$ şeklinde ifade etmişlerdir. Tablo 3'te öğretmen adaylarının geliştirmiş oldukları metaforların kategorileri verilmiştir.

Tablo 3 incelendiğinde, katılımcıların etkin vatandaşlığa yönelik geliştirmiş oldukları metaforlar 7 farklı kategoride toplanmıştır. Bu kategoriler sirasıyla (1) "sosyal sorumluluğun yüksek olduğu etkin vatandaşlı", (2) "değerli bir unsur olarak etkin vatandaşlık", (3) "üretken kimlik/vasıfolarak etkin vatandaşlık", (4) "doğal unsur olarak etkin vatandaşlık", (5) "değgişim ve sürekliliğe açık olarak etkin vatandaşlık", (6) "eğitim-öğretim unsuru olarak etkin vatandaşlık" (7) ve "politik katılım olarak etkin vatandaşlık" kategorileridir. Tablo 3'e göre, "sosyal sorumluluğu yüksek olduğu etkin vatandaşlı" kategorisinde 37 öğretmen adayı toplam 20 farklı metafor geliştirmiştir. Yine "değerli bir unsur olarak etkin vatandaşlık" kategorisinde 21 öğretmen adayının toplam 16 farklı metafor geliştirdikleri görülmektedir. 
Tablo 3. Öğretmen adaylarının etkin vatandaşlık kavramına ilişkin geliştirmiş olduklarn metafor kategorileri

\begin{tabular}{|c|c|c|c|c|}
\hline Kategoriler & Metaforlar & $\begin{array}{l}\text { Meta- } \\
\text { for } \\
\text { Sayilar1 } \\
\text { (n) }\end{array}$ & $\begin{array}{l}\text { Metafor } \\
\text { frekansı } \\
\text { (öğrenci } \\
\text { sayısı) } \\
\text { (f) }\end{array}$ & $\begin{array}{l}\text { Metafor } \\
\text { Yüzdesi } \\
\text { (\%) }\end{array}$ \\
\hline $\begin{array}{l}\text { Sosyal } \\
\text { sorumlu- } \\
\text { luğun } \\
\text { yüksek } \\
\text { olduğu etkin } \\
\text { vatandaşlik }\end{array}$ & $\begin{array}{l}\text { Sorumluluk sahibi kişi (13), duyarlı } \\
\text { insan (4), örnek kişi (2), sosyal ada- } \\
\text { let (2), ayna (1), beyaz gömlek (1), } \\
\text { bilinçli birey (1), bir elin parmakları } \\
\text { (1), binadaki kolon (1), çağdaş insan } \\
\text { (1), çark dişlisi (1), hayat damarı (1), } \\
\text { insan kalbi (1) insan vücudu (1), ev } \\
\text { (1), orkestra elemanı (1), kaleci (1), } \\
\text { saat (1), sosyal katılım (1), temel } \\
\text { yapıtaşı (1) }\end{array}$ & 20 & 37 & 26.81 \\
\hline $\begin{array}{l}\text { Değerli bir } \\
\text { unsur olarak } \\
\text { etkin } \\
\text { vatandaşlık }\end{array}$ & $\begin{array}{l}\text { Elmas (4), altın (2), anne (2), aile (1), } \\
\text { ata (1), can suyu (1), ekmek (1), en- } \\
\text { zim (1), ambulans (1), nefes (1), or- } \\
\text { gan (1), süper kahraman (1), şehit } \\
\text { (1), toprak (1), asker (1), vatan to- } \\
\text { prağ (1) }\end{array}$ & 16 & 21 & 15.21 \\
\hline $\begin{array}{l}\text { Üretken kim- } \\
\text { lik / vasıf } \\
\text { olarak etkin } \\
\text { vatandaşlık }\end{array}$ & $\begin{array}{l}\text { Arı (11), karınca (4), aktif birey (3), } \\
\text { çalışkan öğrenci (3), araç motoru (1), } \\
\text { dinamo (1), Taksi (1), fabrika (1), } \\
\text { işlenmiş kumaş (1), işlenmiş demir } \\
\begin{array}{ll}(1), \text { lokomotif } & (1), \text { makine (1), } \\
\text { makinist (1) } & \end{array}\end{array}$ & 13 & 30 & 21.73 \\
\hline $\begin{array}{l}\text { Doğal unsur } \\
\text { olarak etkin } \\
\text { vatandaşlık }\end{array}$ & $\begin{array}{l}\text { Ağaç (6), su (5), tohum (4), güneş } \\
\text { (2), aslan (1), çiçek (1), gökkuşağ1 } \\
\text { (1), okyanus (1), yağmur damlası } \\
\text { (1), yıldız (1), bankamatik (1) }\end{array}$ & 11 & 24 & 24.63 \\
\hline $\begin{array}{l}\text { Değişim ve } \\
\text { sürekliliğe } \\
\text { açık olarak } \\
\text { etkin } \\
\text { vatandaşlık }\end{array}$ & $\begin{array}{l}\text { Araştırmacı (2), bilgisayar (2), gi- } \\
\text { rişimci (2), kişilik gelişimi (2), ista- } \\
\text { syon (1), aydınlık (1), bilim (1), } \\
\text { teknoloji (1), trafik } \text { ş̧ı̆̆ }^{2}(1)\end{array}$ & 9 & 13 & 9.42 \\
\hline $\begin{array}{l}\text { Eğitim- } \\
\text { öğretim un- } \\
\text { suru olarak } \\
\text { etkin } \\
\text { vatandaşlık }\end{array}$ & $\begin{array}{l}\text { Öğretmen (4), insan (2), mum (1), } \\
\text { müzisyen (1), müzik öğretmeni (1), } \\
\text { okul (1) }\end{array}$ & 6 & 10 & 7.24 \\
\hline $\begin{array}{l}\text { Politik } \\
\text { katılım } \\
\text { olarak etkin } \\
\text { vatandaşlık }\end{array}$ & $\begin{array}{l}\text { Başbakan (1), devlet adamı (1), poli- } \\
\text { tikacı (1) }\end{array}$ & 3 & 3 & 2.17 \\
\hline Toplam & 7 & 78 & 138 & 100 \\
\hline
\end{tabular}


Yine "üretken kimlik/vasıf olarak etkin vatandaşlı" kategorisinde ise 30 öğretmen adayının toplam 13 farklı metafor geliştirdikleri tespit edilmiştir. Yine "doğal unsur olarak etkin vatandaşlık" kategorisinde ise 24 öğretmen adayı toplam 11 farklı metafor geliştirirken, "değişim ve sürekliliğe açı olarak etkin vatandaşlı" kategorisinde 13 öğretmen adayı toplam 9 ve "eğitim-öğretim unsuru olarak etkin vatandaşlık" kategorisinde ise 10 öğretmen adayı toplam 6 farklı metafor geliştirdikleri görülmektedir. Son olarak "politik katılım olarak etkin vatandaşlık" kategorisinde ise 3 öğretmen adayı aynı sayıda farklı metafor geliştirdikleri tespit edilmiştir.

\section{Kategori 1. Sosyal Sorumluluğun Yüksek Olduğu Etkin Vatandaşlık:}

Tablo 3 incelendiğinde, en fazla metaforun geliştirildiği kategori olarak dikkat çekmekte ve bu kategori altında etkin vatandaşlık kavramına yönelik 20 farklı metafor geliştirildiği görülmektedir. Bunlar sırasıyla; sorumluluk sahibi kişi (13), duyarlı insan (4), örnek kişi (2), sosyal adalet (2), ayna (1), beyaz gömlek (1), bilinçli birey (1), bir elin parmakları (1), binadaki kolon (1), çă̆daş insan (1), çark dişlisi (1), hayat damarı (1), insan kalbi (1) insan vücudu (1), ev (1), orkestra elemanu (1), kaleci (1), saat (1), sosyal katılım (1) ve son olarak temel yapıtaşı (1), gibi çeşitli metaforlardan oluşmaktadır. Bu kategori ile ilgili öğretmen adaylarının oluşturmuş oldukları örnek metafor ifadeleri ise şu şekildedir. "Etkin vatandaş sorumluluk sahibi kişi gibidir, çünkü nerede ve nasıl davranacağını bilir. Sadece kendisini değil içinde yaşadığı toplumunu da düşünür." (Ö4). "Etkin vatandaş duyarlı insan gibidir, çünkü duyarlı insan toplumda yapılan haksızlıklara ve kargaşalığa karşı dik durmasın bildiği gibi, çevresindeki olumlu olaylara karşı da takdir etmesini bilir." (Ö103). "Etkin vatandaş aynaya benzer, çünkü kendisi öğrendiğini çevresine yansitır." (Ö87). "Etkin vatandaş bir elin parmakları gibidir, çünkü parmaklar birbirinden ne kadar farklı görünseler de sağlam bir eli bu farklılklar oluşturur." (Ö26). Bu kategori altında geliştirilen metaforlardan anlaşılacağı üzere katılımcılar etkin vatandaşlığı; sorumluluk duygusu yüksek, çevresine karşı duyarlı, birlik ve beraberlik duygusu ön planda olacak şekilde düşündükleri görülmektedir. 


\section{Kategori 2. Değerli Bir Unsur Olarak Etkin Vatandaşlık:}

Tablo 3'e göre bu kategoride araştırmaya katılan 21 katılımcı tarafından etkin vatandaşlıkla ilgili toplam 16 farklı metafor geliştirilmiştir. Bu metaforlar sirasiyla; elmas (4), altın (2), anne (2), aile (1), ata (1), can suyu (1), ekmek (1), enzim (1), ambulans (1), nefes (1), organ (1), süper kahraman (1), şehit (1), toprak (1), asker (1) ve vatan toprağı (1), gibi çeşitli metaforlardan oluşmaktadır. Bu kategoride yer alan metaforlarla ilgili katılımcı görüşleri ise şu şekildedir. "Etkin vatandaş elmasa benzer, çünkü işlendikçe ışıldar." (Ö49). "Etkin vatandaş altın gibidir, çünkü bulunması zordur." (Ö44). "Etkin vatandaş anne gibidir, çünkü anneler de çocuklarının her sorunuyla ilgilenir ve çocuğuna herhangi bir zarar gelmemesi için gerekli tedbirleri alır." (Ö35). "Etkin vatandaş ekmeğe benzer, çünkü her sofrada kullamlabilir ve uyum sağlayabilir." (Ö100). "Etkin vatandaş ambulans gibidir, çünkü kim olduğuna bakmadan olay veya kişilerin yardımına koşar." (Ö78). Bu kategori altında geliştirilen metaforlardan anlaşılacağı üzere katılımcıların etkin vatandaşlığa karşı yaklaşımları olumlu olmakla birlikte etkin vatandaşlığı zihinlerinde değerli gördükleri unsur ve nesnelerle ilişkilendirdikleri görülmektedir.

\section{Kategori 3. Üretken Kimlik/Vasıf Olarak Etkin Vatandaşlık:}

Tablo 3 incelendiğinde bu kategoride araştırmaya katılan 30 öğretmen adayı tarafından etkin vatandaşlıkla toplam ilgili 13 farklı metafor geliştirilmiştir. Bu metaforlar sırasıyla; arı (11), karnca (4), aktif birey (3), çalışkan öğrenci (3), araç motoru (1), dinamo (1), taksi (1), fabrika (1), işlenmiş kumaş (1), işlenmiş demir (1), lokomotif (1), makine (1) ve makinist (1), gibi çeşitli metaforlardan oluşmaktadır. Bu kategoride yer alan metaforlarla ilgili katılımcı görüşleri ise şu şekildedir. "Etkin vatandaş arıya benzer, çünkü tek amacı kovanına yarar sağlamak, verilen görevi layıkıyla yapmak ve üstüne düşen görevi yerine getirmektir." (Ö36). "Etkin vatandaş arl gibidir, çünkü sürekli üretir ve çevresine faydal olur." (Ö60). "Etkin vatandaş karmcaya benzer, çünkü bağh olduğu topluluk için üzerine düşen görevi büyük bir fedakarlik ve istekle yerine getirir." (Ö56). "Etkin vatandaş çalışkan öğrenci gibidir, çünkü çalışkan öğrenci görev ve sorumluluklarını bilen kişidir." (Ö79). "Etkin vatandaş fabrikaya benzer, çünkü bir ülkenin varlığın devam ettirebilmesi için sürekli 
üretmesi gerekir." (Ö89). Bu kategori altında belirtilen görüşlerden anlaşılacağı üzere katılımcılar etkin vatandağlışı, çevresine faydalı, çalışkan ve üretken bir yapıya sahip kişi ve unsurlarla ilişkilendirdikleri dikkat çekmektedir.

\section{Kategori 4. Doğal Unsur Olarak Etkin Vatandaşlık:}

Tablo 3 incelendiğinde bu kategoride araştırmaya katılan 24 öğretmen adayı tarafından etkin vatandaşlıkla toplam ilgili 11 farklı metafor geliştirilmiştir. Bu metaforlar sirasıyla; ağaç (6), su (5), tohum (4), güneş (2), aslan (1), çiçek (1), gökkuşağı (1), okyanus (1), yağmur damlası (1), yıldız (1) ve bankamatik (1) gibi çeşitli metaforlardan oluşmaktadır. Bu kategoride yer alan metaforlarla ilgili katılımc görüşleri ise şu şekildedir. "Etkin vatandaş ağaca benzer, çünkü ağaçları günlük hayatımızda çok fazla fark etmesek te fakat onlar bulundukları yerde oksijen üreterek etkin bir şekilde rol oynarlar." (Ö95). "Etkin vatandaş su gibidir, çünkü bazen bulunduğu kabın şeklini alır, bazen de en sert cisimleri bile parçalar." (Ö50). "Etkin vatandaş suya benzer, çünkü olması gerektiği gibi olmalıdır, yani katkısız ve temiz." (Ö112). "Etkin vatandaş tohum gibidir, çünkü uygun ortam sağlandığında etkin olduğu konudaki bilgilerini dışa yansitır." (Ö67). "Etkin vatandaş güneşe benzer, çünkü onun gibi toplumu aydinlatır." (Ö66). "Etkin vatandaş yağmur damlası gibidir, çünkü gittiği her yere her toprağa bolluk ve bereket götürür." (Ö17). Bu kategoride yer alan betimlemelere göre katılımcılar etkin vatandaşlığı, doğal, olduğu gibi görünen ve çevresine faydalı durumlarla ilişkilendirdikleri görülmektedir.

\section{Kategori 5. Değişim ve Sürekliliğe Açık Olarak Etkin Vatandaşlık:}

Tablo 3'e göre bu kategoride araştırmaya katılan 13 katılımcı tarafından etkin vatandaşlıkla ilgili toplam 9 farklı metafor geliştirilmiştir. Bu metaforlar sırasıyla; araştırmacı (2), bilgisayar (2), girişimci (2), kişilik gelişimi (2), istasyon (1), aydınlık (1), bilim (1), teknoloji (1), trafik ışı̆̆ı (1) gibi çeşitli metaforlardan oluşmaktadır. Bu kategoride yer alan metaforlarla ilgili katılımcı görüşleri ise şu şekildedir. "Etkin vatandaş araştırmacı gibidir, çünkü karşılaştığı sorunları, merak ettiği şeyleri araştıran ve bunlara çözüm üreten kişidir." (Ö88). "Etkin vatandaş bilgisayara benzer, çünkü her işi rahatlıkla ve zorlanmadan yerine getirir ve beklentileri karşılar." (Ö40). "Etkin 
vatandaş teknolojiye benzer, çünkü değişime açık, sosyal ve çağa ayak uydurarak çă̆ın gerisinde kalmaz." (Ö73). "Etkin vatandaş bilim gibidir, çünkü sürekli kendini yeniler ve çă̆a uyum să̆lar." (Ö30). "Etkin vatandaş trafik ışı̆̆ına benzer, çünkü ne zaman yanıp söneceğinin farkındadır, yani ne vakit ne yapacă̆ın bilir." (Ö90). "Etkin vatandaş istasyona benzer, çünkü sürekli hareket, değişim ve gelişim içerisindedir." (Ö76). Burada belirtilen görüşler dikkate alındığında etkin vatandaş, durağan olmayan, sürekli kendini geliştiren, yenilik ve değişimlere açık olmalıdır.

\section{Kategori 6. Eğitim-Öğretim Unsuru Olarak Etkin Vatandaşlık:}

Tablo 3 incelendiğinde bu kategoride araştırmaya katılan 10 öğretmen adayı tarafından etkin vatandaşlıkla toplam ilgili 6 farklı metafor geliştirilmiştir. Bu metaforlar sirasıyla; öğretmen (4), insan (2), mum (1), müzisyen (1), müzik öğretmeni (1) ve okul (1) gibi çeşitli metaforlardan oluşmaktadır. Bu kategoride yer alan metaforlarla ilgili katılımcı görüşleri ise şu şekildedir. "Etkin vatandaş öğretmene benzer, çünkü en önemli mesleği yapan kişi olarak öğrencilerin hayatlarında fark oluşturmayı ve onları geliştirmeyi amaçlar." (Ö86). "Etkin vatandaş mum gibidir, çünkü çevresini aydınlatır ve çevresine yararl olur." (Ö121). "Etkin vatandaş müzisyene benzer, çünkü toplumdaki duruşunu müziğiyle göstermeye çalışan ve daha iyisini yapmak için uğraşan kişidir." (Ö65). Bu kategoride ifade edilen duygu ve düşüncelere göre etkin vatandaş/vatandaşlık bireylerin hem kendisine hem de çevresine faydalı olma durumlarıyla ilişkilendirildiği görülmektedir.

\subsection{Kategori 7. Politik Katılım Olarak Etkin Vatandaşlık:}

Tablo 3'e göre bu kategoride araştırmaya katılan 3 katılımcı tarafından etkin vatandaşlıkla ilgili toplam 3 farklı metafor geliştirilmiştir. Bu metaforlar sırasıyla; başbakan (1), devlet adamı (1) ve politikacı (1) gibi çeşitli metaforlardan oluşmaktadır. Bu kategoride yer alan metaforlarla ilgili katılımcı görüşleri ise şu şekildedir. "Etkin vatandaş başbakan gibidir, çünkü kendini her yönüyle geliştirmiş ve sorumluluklarının farkındadır." (Ö12). "Etkin vatandaş devlet adamı gibidir, çünkü devlet adamı sadece ülkesinin gelişimine katkı sağlamaz aynı zamanda her vatandaş gibi onlarında görev ve sorumlulukları 
vardır." (Ö9). "Etkin vatandaş politikacı gibidir, çünkü kendine özgü politik düşüncesi vardır ve bunu zamanı geldiğinde ifade eder." (Ö31). Burada belirtilen görüşlere göre katılımcıların etkin vatandaşlık algısı, belirli ölçüde çevresine etki edebilen ve lider pozisyonundaki kişilerle yakından ilişkili olduğu anlaşılmaktadır.

\section{Tartışma ve Sonuç}

Etkin vatandaşlık kısaca bireylerin toplum içerisindeki görev ve sorumluluklarının farkında olması ve toplumun her kesiminden vatandaşların daha katılımcı olmalarını ifade eder. Bu araştırma sonuçları dikkate alındığında katılımcıların genellikle etkin vatandaşlığı bireylerin sorumluluk sahibi, toplum içinde görevlerini en iyi şekilde yerine getiren, sosyal sorunlara karşı duyarlı ve çeşitli açılardan vasıflı niteliklerle tanımlamışlardır. Araştırmada ulaşılan bu sonuç Eryılmaz, Bursa ve Ersoy (2018), İbrahimoğlu (2009), Ersoy (2008) ve Aydın ve Çelik (2017) gibi çalışma sonuçlarıyla benzerlik göstermektedir. Sırasıyla ilgili araştırma sonucuna göre katılımclar etkin vatandaşlığı siyasal ve sosyal katılım yerine genellikle hak ve sorumluluklarının farkında, dürüst, çalışkan ve duyarlı kişiler olarak tanımlamışlardır. Yine bu çalışma sonucuna göre Türkiye'de etkin vatandaşlık ve sivil toplum anlayışının güçlü olmadığ1 vurgusu yapılmıştır. Bir diğer çalışma sonucuna (İbrahimoğlu, 2009) göre ise vatandaşlık kavramı sadece devlet ile birey arasındaki bir bağ olarak görülmekte ve değerleriyle barışık toplumsal ilişkilerin iyi olduğu durumu ifade etmektedir. Ayrıca bireylerin etkin vatandaş olarak değerlendirilebilmesi için katılımcı, sosyal hayata duyarlı, üretken, iletişimi güçlü ve demokratik değerleri benimsemiş olması gerekir. Yine Ersoy (2008)'un yapmış olduğu çalışma sonucuna göre katılımcılar etkin vatandaşlığı çoğunlukla hak ve sorumluluklarını bilen, kullanan, başkalarına karşı saygılı, dürüst, vatanını ve milletini seven, insanlığ 1 ilgilendiren sorunlara karşı ilgili kişiler olarak ifade etmişlerdir. Martin ve Chiodo (2007), öğrencilerin vatandaşlık hakkındaki görüşlerini inceledikleri çalışmasında katılımcılar vatandaşlığı genellikle yardımsever, kurallara bağlı ve saygılı gibi kategorilerle ilişkilendirmişlerdir.

Araştırmada etkin vatandaşlık kavramına yönelik katılımcıların algılarının farklılaştığı ve çeşitli metaforlar ürettikleri gözlenmiştir. Benzer 
çalışma sonuçları incelendiğinde (Mahlios ve Maxson, 1998; Shaw ve Mahlios, 2008; Seferoğlu, Korkmazgil ve Ölçü, 2009; Aydın, 2010; Geçit ve Gençer, 2011; Kalra ve Baveja, 2012; Kılcan ve Çepni, 2015; Çetin ve diğ, 2015; Gökçe, 2016; Aydın ve Çelik, 2017; Turan, 2017; Alım, Şahin ve Meral, 2018; Değirmenci, 2019) katılımcıların araştırmalara konu olan kavram veya durumlarla ilgili farklı sayılarda metafor ürettikleri görülmektedir. Araştırmaya katılan sınıf öğretmeni adayları etkin vatandaşlık kavramına yönelik geliştirmiş oldukları metaforlar ortak özelliklerine göre ilişkilendirildiğinde 7 farklı kategoride toplandığı görülmektedir. Benzer çalışma sonuçları incelendiğinde (Gökçe, 2016; Turan, 2017; Seferoğlu, Korkmazgil ve Ölçü, 2009; Aydın ve Çelik, 2017; Alım, Şahin ve Meral, 2018; Değirmenci, 2019) katılımcıların geliştirmiş oldukları metaforlar çeşitli özelliklerine göre farklı sayıda kategoriler altında toplandığı görülmektedir.

Metaforlar, insanların zihinsel süreç ve bilinç yapılarıyla doğrudan ilişkilidir. Araştırmada etkin vatandaşlık kavramına yönelik katılımcılar tarafından üretilen metaforlar incelendiğinde katılımcilar etkin vatandaşlığı çoğunlukla sorumluluk sahibi kişi, arı, ağaç, su, elmas, altın, karınca, öğretmen, tohum, çalışkan öğrenci, aktif birey, duyarlı insan, anne, güneş, örnek kişi gibi olumlu sembollerle ilişkilendirdikleri dikkat çekmektedir. Yapılan bazı çalışmalarda (Ersoy, 2007; Feldmann 2007; Tuncel ve Uğur (2009), Peterson ve Knowles (2009), Göl, 2013; Keleş ve Tonga, 2014; Aydın ve Çelik, 2017) vatandaşlık ve etkin vatandaşlığa yönelik algının genellikle olumlu yönde olduğu dikkat çekmektedir.

Sonuç olarak yerel ve küresel ölçekte yaşanan olay ve sorunlar, teknoloji ve bilimsel alanda yaşanan hızlı gelişmeler günümüzde etkin bireylere ve her alanda katılım oranının yüksek olduğu kişilere ihtiyaç bulunduğunu göstermektedir. Hak ve sorumluluklarının farkında, bilinçli kararlar alabilen, demokratik anlayışı benimsemiş, katılımcı ve sosyal sorumluluk sahibi bireyler ülkelerin geleceği adına da önemlidir. $\mathrm{Bu}$ nedenle eğitim ortamlarında bireylere vatandaşlık eğitimi için gerekli bilgi, beceri ve değerler kazandırılarak etkin vatandaşlık bilinci oluşturulmalıdir. 


\section{Öneriler}

- Eğitim ortamlarında sorumluluk duygusu yüksek, bilinçli ve etkin vatandaşlık becerilerine sahip bireylerin yetiştirilmesi adına çeşitli uygulama ve etkinliklere yer verilebilir.

- Etkin vatandaşlık bilincinin artırılması için başta coğrafya ve sosyal bilgiler öğretim programları olmak üzere diğer benzer programlarda bu amaçla ilgili bilgi, beceri ve kazanımlara daha fazla öncelik verilebilir.

- Bireylerde etkin vatandaşlık bilincinin artması için yakın çevre ve yaşam alanlarında karşılaşılan örnek durum veya olaylarla ilgili gezi ve etkinlikler yapılabilir.

- Bireylerde sorumluluk duygusu ve etkin vatandaşlık bilincinin artmasına yönelik sosyal ve çevre ile ilgili çeşitli projeler yapılabilir.

- Eğitim fakültelerinin lisans programlarında yer alan topluma hizmet uygulamaları dersi etkin vatandağlık eğitimi kapsamında yararlı uygulama ve etkinliklerde değerlendirilebilir. 


\title{
EXTENDED ABSTRACT
}

\section{Examination of Prospective Teachers' Perceptions of Active Citizenship}

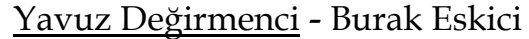 \\ * \\ Bayburt Üniversitesi
}

In today's complicated and rapidly-changing world, there is a need for exploratory individuals who can question, think critically, and have the ability to make conscious decisions about the present and the future. Besides, societies need citizens who are interested in the developments taking place at local and global levels, conscious of their responsibilities, sensitive about social events and problems, and can assume effective roles when needed. Therefore, education has a significant role in raising such individuals who are needed for the society, and citizenship education and approaches come into prominence.

In fact, citizenship education started with the development of the concept of citizen, and has been formed in line with the developments in the understanding of citizenship. It can be said that the fundamental changes in the understanding of citizenship are in parallel with the social, political, economic and cultural changes of societies; and therefore, each nation's understanding of citizenship and citizenship education which it applies accordingly are different from those of other nations (Ersoy, 2007). The limitations directed towards understanding of the concept of citizenship appear as determinants of the coverage of the citizenship education. Particularly, the concept of active (effective) citizenship, which we have frequently been coming across recently, is accepted as an approach with a universal coverage (Hablemitoğlu and Özmete, 2012), and is defined in different ways.

\section{Method}

In this study which examines prospective classroom teachers' metaphors 
regarding the concept of active citizenship, the phenomenological design, a type of qualitative research method, was employed. This design is referred to as focusing on phenomena of which we are aware in our daily lives, but about which we do not have in depth and detailed understanding. Those phenomena can appear in such different forms as events, experiences, perceptions, concepts, tendencies and situations in the world in which we live. Therefore, the phenomenological design is a method used in studying phenomena which we are not completely foreign to, but we cannot completely conceive, either (Ylldırım and Şimşek, 2011). Phenomenological studies define the common meaning of people's experiences regarding a phenomenon or a concept (Creswell, 2016). The technique of content analysis has been used to analyze the data obtained from the participants of the research. Content analysis is a technique which is widely used in social sciences to classify the data in different ways, gathering significant concepts and themes under main groups, regulating and interpreting them in such a way to be understood by readers easily (Bilgin, 2014; Yıldırım and Şimşek, 2011).

\section{Findings, Discussion and Results}

The examination of the research reveals that the metaphors which were developed by the participants about the concept of active citizenship were grouped in 7 different categories. Those categories are: (1) "active citizenship with high social responsibility", (2) "high social responsibility as a valuable element", (3) "active citizenship as productive ID/qualification", (4) "active citizenship as a natural element", (5) "active citizenship which is open to change and sustainability", (6) "active citizenship as an element of education", and (7) "active citizenship as political participation."

Active citizenship refers briefly to the awareness of people of their duties and responsibilities in the society, and more participation of citizens from every segment of the society. The findings of the research show that the participants have defined active citizenship with such characteristics as assuming responsibilities, performing responsibilities in the society properly, and being sensitive towards social problems and qualified in many aspects. The results obtained have similarities with the findings of studies by Eryılmaz, Bursa and Ersoy (2018), İbrahimoğlu (2009), Ersoy 
(2008), and Aydın and Çelik (2017). It has been observed in the research that the perceptions of the participants vary and they produce several metaphors. When the findings of similar studies are examined, it is observed that participants form metaphors in different numbers about the concepts or situations subject to the researches.

Metaphors are directly related to people's mental processes and structures of consciousness. The examination of the metaphors that were formed by the participants about the concept of active citizenship draws attention to the fact that the participants mostly related active citizenship with such positive symbols as responsible person, bee, tree, water, diamond, ant, teacher, seed, hardworking student, active individual, sensitive person, mother, sun and pacemaker. Some studies show that the perceptions about citizenship and active citizenship are generally positive (Ersoy, 2007; Feldmann 2007; Tuncel and Uğur (2009), Peterson and Knowles (2009), Göl, 2013; Keleş and Tonga, 2014; Aydın and Çelik, 2017).

As a result, the events and problems being experienced at the domestic and global scales, as well as the rapid technological and scientific developments show that there is need for individuals who are more active and have a high participation rate in any field. Having individuals who are aware of their rights and responsibilities, can make conscious decisions, assume a democratic understanding, have participatory and social responsibility are of significant importance for futures of countries. Therefore, individuals should be given the necessary information, skills and values about citizenship education in educational environments, so that a consciousness of active citizenship can be established.

\section{Kaynakça / References}

Akbaş, Y. ve Uzunöz, A. (2011). Kavramsal değişim yaklaşımına dayalı coğrafya öğretimi: bir uygulama örneği. e-Journal of New World Sciences Academy. 6 (2), 1659-1678.

Akturan, U. ve Esen, A. (2008). Fenomenoloji. Nitel araştırma yöntemleri, (Edit: Baş, T. ve Akturan, U.). Ankara: Seçkin yayıncılık.

Akyol, Y. ve Özünal, S. (2015). Ortaokul Türkçe ders kitaplarının etkin vatandaş yetiştirme açısından incelenmesi. Journal of Language and Literature Education, 14, 193-211. 
Alım, M., Şahin, İ. F. ve Meral, E. (2018). Coğrafya öğretmen adaylarının (pedagojik formasyon) öğretmen kavramına ilişkin algıları. Atatürk Üniversitesi Sosyal Bilimler Enstitüsü Dergisi, 22 (2), 1113-1127.

Aydın, F. (2010). Ortaöğretim öğrencilerinin coğrafya kavramına ilişkin sahip oldukları metaforlar. Kuram ve Uygulamada Eğitim Bilimleri, 10 (3), 1293-1322.

Aydın, M. ve Çelik, T. (2017). Ortaokul öğrencilerinin etkin yurttaşlık ve hukuk kuralları kavramlarına yönelik metaforik algılarının incelenmesi. PAU Eğitim Fakültesi Dergisi, 42, 29-43.

Bednarz, S. W. (2003). Citizenship in Post-9/11 United States: A role for geography education? International research in Geographical and Environmental Education, 12 (1), 72-80.

Bilgin, N. (2014). Sosyal bilimlerde içerik analizi. Ankara: Siyasal kitabevi.

Büyüköztürk, Ş., Çakmak, E. K., Akgün, Ö. E., Karadeniz, Ş., ve Demirel, F. (2014). Bilimsel araştırma yöntemleri. Ankara: Pegem yayınları.

CDÖP (2018). Coğrafya dersi öğretim programı. Ankara: Milli eğitim bakanlığg ortaöğretim genel müdürlüğü.

Chistolini, S. (2013). Knowledge of the earthquake and school education in the perspective of active citizenship. Journal of US-China Public Administration, 10 (7), 690-700.

Council of EU. 2009. Council conclusions of 12 may 2009 on a strategic framework for European Cooperation in education and training ('ET 2020'). OJ C, 119, May 28.

Creswell, J. W. (2016). Nitel araştırma yöntemleri: Beş yaklaşıma göre nitel araştırma ve araştırma deseni. (Çev. Edit. Bütün, M. ve Demir, S. B.). Ankara: Siyasal Kitabevi.

Çermik, F., Çalışoğlu, M., ve Tahiroğlu, M. (2016). Sınıf öğretmenlerinin küresel vatandaşlık eğitimi ile ilgili görüşlerinin incelenmesi. Turkish Studies, 11 (3), 775-790.

Çetin, T., Kılcan, B., Güneş, C. ve Çepni, O. (2015). Examining secondary school students' perceptions of the concept of migration: A qualitative study. International Journal of Education, 7 (3), 97-120.

Çevik-Kansu, C. (2015). İlkokul 4. Sinıf öğrencilerinde etkin vatandaşlık eğitiminin etkililiği. Yayınlanmamış doktora tezi, Ondokuz Mayıs Üniversitesi Eğitim Bilimleri Enstitüsü. Samsun. 
Değirmenci, Y. (2019). An examination of metaphors regarding the concept of "natural disaster" developed by prospective classroom teachers. International Journal of Geography and Geography Education, 39, 83-94.

Ersoy, A. F. (2007). Sosyal bilgiler dersinde öğretmenlerin etkili vatandaşlık eğitimi uygulamalarına ilişkin görüşleri. Yayınlanmamış Doktora Tezi, Anadolu Üniversitesi Eğitim Bilimleri Enstitüsü, Eskişehir.

Eryılmaz, Ö., Bursa, S., Ersoy, A. F. (2018). Social studies teachers' and students' perceptions of active citizenship and non-governmental organisations. International Online Journal of Educational Sciences, 10 (2), 258-276.

Feldmann, D. (2007). Citizenship education: Current perspectives from teachers in three states. Educational Research Quarterly, 30 (4), 3-15.

Geçit, Y. ve Gençler, G. (2011). Sınıf öğretmenliği 1. sınıf öğrencilerinin coğrafya algilarının metafor yoluyla belirlenmesi (Rize Üniversitesi örneği). Marmara Coğrafya Dergisi, 23, 1-19.

Gökçe, N. (2016). Sosyal bilgiler öğretmen adaylarının coğrafya kavramına ilişkin metaforları. Uluslararası Eğitim Bilimleri Dergisi. $3(9), 121-134$.

Göl, E. (2013). Sosyal bilgiler öğretmen adaylarının küresel vatandaşlık tutum düzeylerinin farklı değişkenler açısından incelenmesi. Yayımlanmamış yüksek lisans tezi. Ahi Evran Üniversitesi Sosyal Bilimler Enstitüsü. Kırşehir.

Hablemitoğlu, Ş. ve Özmete, E. (2012). Etkili vatandaşlık eğitimi için bir öneri. Ankara Sağllk Bilimleri Dergisi, 1(3), 39-54.

Hoskıns, B. (2006). Draft framework on indicators for active citizenship. Ispra: CRELL.

İbrahimoğlu, Z. (2009). Sınıf öğretmeni adaylarının etkin vatandaş tanımları ve etkin vatandaş yetiştirmede sosyal bilgiler dersine yükledikleri rol. A. Şişman ve diğ. (Edit.), I. Uluslararası Avrupa Birliği, demokrasi, vatandaşlık ve vatandaşlık eğitimi sempozyumu bildiriler kitabı. Uşak Üniversitesi.

Kalra, M. B. ve Baveja, B. (2012). Teacher thinking about knowledge, learning and learners: a metaphor analysis. Procedia - Social and Behavioral Sciences, 55, 517-326. 
Kara, C., Topkaya, Y. ve Şimşek U. (2012). The place of active citizenship education in the social studies curriculum. Zeitschrift Für Die Welt Der Türken Journal of World of Turks, 4(3)147-159.

Keleş, H. ve Tonga, D. (2014). Öğrencilerin vatandaşlık bilincini etkileyen faktörlere ilişkin öğretmen görüşleri. Abant İzzet Baysal üniversitesi Ĕ̆itim Fakültesi Dergisi, 14 (2), 61-85.

Kennedy, K. J. (2007). Student constructions of 'active citizenship': what does participation mean to students? British Journal of Educational Studies, 55 (3), 304-324.

Kılcan, B. ve Çepni, O. (2015). A qualitative examination of the perceptions of the eight grade students regarding the concept of environmental pollution. Journal of International Environmental Application $\mathcal{E}$ Science, 10(2), 239-250.

Mahlios, M. ve Maxson, M. (1998). Metaphors as structures for elementary and secondary preservice Teachers' thinking. International Journal of Educational Research, 29, 227-240.

Martın, L. ve Chiodo, J. (2007). Good citizenship: what students in rural schools have to say about it. Theory and research in social education, 35 (1), 112- 134.

MEB (2018). Sosyal bilgiler dersi öğretim programı. Milli eğitim bakanlı̆̆ı. Ankara.

Miles, M. B., ve Huberman, M. A. (1994). An expanded sourcebook qualitative data analysis. London: Sage.

Morgan, G. (1997). Yönetim ve örgüt teorilerinde metafor. Gündüz Bulut (Çev.) İstanbul: Mess Yayın.

NCSS. (2014). National council for the social studies. Retrieved from https://www.socialstudies.org/positions/human_rights_education_2014. Erişim Tarihi: 22.12.2018.

Patrick, J. J. (2003). Essential elements of education for democracy: What are they and why should they be at the core of the curriculum in schools? http://www.civiced.org/pdfs/EEOEforDemocracy.pdf. Erişim Tarihi: 20.12.2018.

Peterson, A. ve Knowles, C. (2009). Active citizenship: A preliminary study into student teacher understandings. Educational Research, 51(1), 39- 59. 
Phillıps, L. (2011). Possibilities and quandaries for young children's active citizenship. Early Ducation and Development, 22(5), 778-794.

Saban, A. (2008). Okula ilişkin metaforlar. Kuram ve Uygulamada Ĕ̆itim Yönetimi, 55,459-496.

Saban, A. (2009). Öğretmen adaylarının öğrenci kavramına ilişkin sahip oldukları zihinsel imgeler. Türk Eğitim Bilimleri Dergisi, 7 (2), 281326.

Seferoğlu, G., Korkmazgil, S. ve Ölçü, Z. (2009). Gaining insights into teachers' ways of thinking via metaphors, Educational Studies, 35 (3), 323-335.

Shaw, D. M. ve Mahlios, M. (2008). Pre-Service teachers' metaphors of teaching and literacy. Reading Psychology, 29 (1), 31-60.

Şimşek, U., Tıkman, F., Yıldırım, E. ve Şentürk, M. (2017). Sosyal bilgiler ve sınıf eğitimi öğretmen adaylarının gözünden vatandaşlık eğitimi: Nitel bir çalışma. Dicle Üniversitesi Ziya Gökalp Ĕ̆itim Fakültesi Dergisi, 32, 913-925.

Tuncel, G. ve Uğur, A. C. (2009). İlköğretim 8. sınıf öğrencilerinin “küresel vatandaşlık" kavramına yükledikleri anlamlar üzerine bir değerlendirme, I. Uluslararası Avrupa Birliği, demokrasi, vatandaşlık ve vatandaşlık eğitimi sempozyumu bildiriler kitabı. Uşak Üniversitesi.

Turan, İ. (2017). Sınıf öğretmeni adayların nükleer santralle ilgili metaforları. International Journal of Economic Studies, (4), 569-579.

Yıldırım, A. ve Şimşek, H. (2011). Sosyal bilimlerde nitel araştırma yöntemleri. Ankara: Seçkin yayıncılık.

Zepke, N. (2013). Lifelong education for subjective well-being: how do engagement and active citizenship contribute? International Journal of Lifelong Education, 32 (5), 639-651.

\section{Kaynakça Bilgisi / Citation Information}

Değirmenci, Y. ve Eskici, B. (2019). Öğretmen adaylarının etkin vatandaşlık algılarının incelenmesi. OPUS-Uluslararası Toplum Araştırmaları Dergisi, 11(18), 232-256. DOI: 10.26466/opus.537074. 